\title{
Stem collar rot of passion fruit caused by Fusarium solani in Zhanjiang, China
}

\author{
Yuhan Zhou ${ }^{1} \cdot$ Yuelian Liu $^{1} \cdot$ Jianrong Tang ${ }^{1} \cdot$ Xuhua X X $^{1}$ \\ Received: 26 August 2020 / Accepted: 11 February 2021 / Published online: 22 March 2021 \\ (c) Società Italiana di Patologia Vegetale (S.I.Pa.V.) 2021
}

Keywords Passiflora edulis $\cdot$ Fusarium solani $\cdot$ Collar rot

In May 2019, collar rot was observed on Passiflora edulis (purple passion fruit) with a $43.6 \%$ incidence (600 plants in the field) in Zhanjiang (21.17 N, 110.18E), China. The first aboveground symptom was leaf wilt, followed by necrotic girdling of the plant collar, and, lastly, death. Five diseased samples were cut into 1-2 mm pieces, surfacedisinfested with $2 \%$ sodium hypochlorite $(\mathrm{NaOCl})$, and incubated on potato dextrose agar at $28{ }^{\circ} \mathrm{C}$ for 3 days. The colonies were white. Microconidia were hyaline, ovoid, 9.8 to $13.7 \mu \mathrm{m} \times 2.2$ to $6.7 \mu \mathrm{m}(\mathrm{n}=40)$. Macroconidia were falciform, 3 - to 4 -septate, 36.4 to $47.8 \mu \mathrm{m} \times 4.5$ to $6.7 \mu \mathrm{m}$ $(n=40)$. Chlamydospores were spherical in chains. The morphological characteristics of the isolates were consistent with the description of Fusarium solani (Summerell et al. 2003). A representative isolate (PAR-1) was selected for further characterization. The internal transcribed spacer (ITS), translation elongation factor $(E F 1-\alpha)$, and $\beta$-tubulin genes were amplified and sequenced with the primer pairs ITS1/ITS4, EF-1 $\alpha$-F/EF-1 $\alpha-\mathrm{R}$, and Beta-F/Beta-R (O’Donnell 2000), respectively. The ITS (MN646253), EF1$\alpha$ (MN692915), and $\beta$-tubulin (MN692927) sequences are $100 \%$ identical to $F$. solani. Phylogenetic analyses of the EF1 sequences clustered PaR-1 with $F$. solani. Therefore, PaR-1 was determined as $F$. solani. Pathogenicity test was performed by inoculating the base with mycelial plugs of PaR-1 or agar plugs (as control) (five plants for each, one plug per plant, $P$. edulis, one-month-old). The experiment was conducted three times. The plants were grown in pots in a greenhouse at $28{ }^{\circ} \mathrm{C}$. The symptoms in the field were exhibited by the inoculated plants after only 7 days, and the strains that were identified as members of $F$. solani were rei-

Yuelian Liu

bananafield@126.com

1 Guangdong Ocean University, Zhanjiang, Guangdong, China solated from the inoculated base. $F$. solani has been reported to cause collar rot on P. edulis in Uganda (Emechebe and Mukiibi 1976) and Fujian, China (Li et al. 1993). To our knowledge, this is the first report of $F$. solani-induced collar rot on P. edulis in Zhanjiang, China.

Funding This study was funded by the Postgraduate Education Innovation Program of Guangdong Ocean University (grant number 201929) and the Science and Technology Project of Guangdong Province (grant number 2014A020208119).

\section{Declarations}

Conflict of interest Authors Yuhan Zhou, Yuelian Liu, Jianrong Tang, and Xuhua $\mathrm{Xu}$ all declare that they have no conflict of interest.

Research involving humans and animals This article does not contain any studies with human participants or animals performed by any of the authors.

\section{References}

Donnell K (2000) Molecular Phylogeny of the Nectria haematococcaFusarium solani Species Complex. Mycologia 92:919-938

Emechebe AM, Mukiibi J (1976) Nectria collar and root rot of passion fruit in Uganda. Plant Dis Rep 60:227-231

Li DF, Yang JQ, Zhang XY, Sun LF (1993) Identification of the pathogen causing collar rot of passion fruit in Fujian. Acta Phytopathologica Sinica 23:372

Summerell BA, Salleh B, Leslie JF (2003) A Utilitarian Approach to Fusarium Identification. Plant Dis 87:117

Publisher's Note Springer Nature remains neutral with regard to jurisdictional claims in published maps and institutional affiliations. 